\title{
Disaster Management and Working with Displaced Persons (Methodological Paper)
}

\author{
Odeyoyin Yusuph Abiodun'1, Adekanmbi C. Odunayo², Sana Ayub³ ${ }^{3}$ Mamta Kumari ${ }^{4}$ \\ ${ }^{1}$ University of Rwanda, College of Medicine and Health Sciences, Department of Occupational Therapy, Kigali, Rwanda \\ ${ }^{2}$ SRM Institute of Science and Technology, Chennai, India \\ ${ }^{3}$ Disabled Children Association, Alras, Saudi Arabia \\ ${ }^{4}$ University of Rwanda, College of Medicine and Health Sciences, Kigali, Rwanda \\ Email: Abedex4real@yahoo.com
}

How to cite this paper: Abiodun, O.Y., Odunayo, A.C., Ayub, S. and Kumari, M. (2021) Disaster Management and Working with Displaced Persons (Methodological Paper). Open Journal of Therapy and Rehabilitation, 9, 29-41.

https://doi.org/10.4236/ojtr.2021.92003

Received: November 3, 2020

Accepted: March 9, 2021

Published: March 12, 2021

Copyright $\odot 2021$ by author(s) and Scientific Research Publishing Inc. This work is licensed under the Creative Commons Attribution International License (CC BY 4.0).

http://creativecommons.org/licenses/by/4.0/

\begin{abstract}
This methodological paper explains the process of occupational therapy management of displaced persons due to disaster influence. It is yet to be part of the occupational therapy practice domain even in recent decades with the advancement in occupational therapy research evidence and development. It is based on the current knowledge and developments in occupational therapy client centered practice. This methodological and conceptual based study describes and illustrates the occupational therapy practice model of rehabilitating displaced persons due to disaster influence. The present paper explores the occupational therapy role in rehabilitating displaced persons through People's Environmental Occupation, Ecology of Human Performance (EHP), and Occupational Therapy Practice Framework. These are integrated as a single conceptual model to describe how and process of occupational therapy practice area during the rehabilitation process of a displaced person(s). The paper finally presented a sequenced framework to guide occupational therapists practice in this new emerging practice area of rehabilitation. This study was developed based on three different theories to support the occupational therapy treatment process of a displaced person due to disaster of any nature. Its concept based without any statistical analysis.
\end{abstract}

\section{Keywords}

Disaster, Displacement, PEO, EHO, Occupational Performance, Rehabilitation

\section{Introduction}

Disasters aren't aberrant phenomena, they are mainly reflections of the ways human beings live their normal lives because disaster disrupts in resources, in- 
terrupts set-up programs, affects investment, and implicates social and political system of a nation [1]. Disaster usually wipes off the hard earn results of years of development in a short period like a flood, storms, and droughts. The foundational causes of most of these disasters have been attributed to global warming and environmental degradation [2].

Majorly, urbanization, climate changes, population growth and environmental degradation are the sole reasons for the steady rise in disaster over the decades [3]. The European Union, therefore, has included disaster prevention and management in their policy areas alongside health, environment, climate change adaptation, development, cohesion, research and innovation [4].

The most common highlighted causes for disaster in Europe are floods, followed by storms, heat, cold waves, ice, snow, forest fires and man-made disasters, industrial accidents, transport accidents, terrorist attacks, and cyber-attack.

\section{Disaster Management and Working with Displaced Person}

Recent decades have witnessed tremendous disasters of different nature/origin and the role of occupational therapy varies with the context.

According to the world global disaster report [5], around 58\% of the total numbers of people were killed in natural disaster between 1996-2005 from countries of South East region and its postulated that in recent decades, Asia has the highest number of natural and technological disasters [6].

Giving a world report on the disaster and its impact on global development, the infrastructural developments of the African region have been limited due to various disasters confronting the region for over 35 years which has hindered the economic, political and geographical development of many of these African countries. In turn, the majority of the affected people displaced away from their various homes for safety measures and functional engagement resourcefulness of the African nation has been damaged by several disasters [7]. This has made Africa be more resilient to threats facing them today. Although, it is postulated that in the recent decade, Asia had the highest number of natural and technological disasters [8].

People of China, India, and Indonesia are among those at extreme risk of natural disaster [9]. The Incidence and nature of disaster in recent days cannot be prevented by assistive technologies and other advanced gadget.

This has been a cause for alarm leaving many people in the affected area relocating, displaced, dead, occupational imbalanced, handicapped and functionally deprived of their existence as humans.

People are usually displaced from their environmental context due to various disasters confronting them. For example, Figure 1.

\subsection{Natural Disasters}

Natural disasters are Blizzards, extreme heat, earth quakes, floods, tsunamis, 


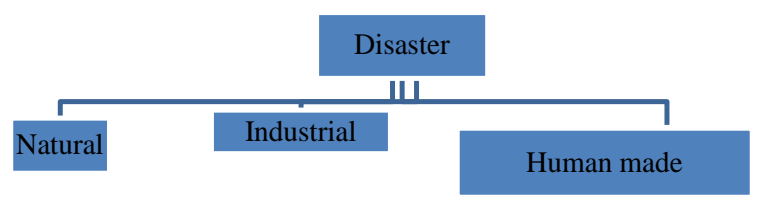

Figure 1. Disaster classification.

volcanic eruptions, ash fall, hurricanes, cyclones, tornados, lightning strikes, avalanches, land ships, and fire outbreaks. A natural disaster is a devastating event that endangers people's lives and property. Although there is often little that can be done to prevent a natural disaster but people can take steps to reduce the effect that it has on themselves and their property.

\subsection{Industrial Disasters}

Industrial disasters are Gas leaks, chemical spills, air-line crashes, nuclear accidents, exposure to noxious agents or toxic waste, dam failure, electrical fires, construction or plant accidents, suspicious goods, bombing threats, gang behaviours, assaults, hostage situations, student riots, trespassers, violent intruders, shootings, and other threats [10].

\subsection{Human Made Disaster}

Man-made disasters are examples of specific cases where man-made hazards have become reality in an event. The rising population has resulted in high fuel consumption and reduction of natural resources. Over population also affects our social environment. Another type of disaster that falls in this category is a nuclear bomb. Other types of man-made disasters that are just as catastrophic include chemical spill, oil spill, arson, and terrorism.

In the current Era, human made disasters have been the utter most factors affecting citizens of various countries. Logically, these happenings are due to government/political influence affecting the economy and security of the involved nation living many individual homeless, traumatize, depressed, stressed and deprived of their formal right within their context of existence [11]. Owing to the forceful deprivation, threat and inadequate safety precaution, people are either actively or passively force to unhappily relocate away from their comfort zone to an undesired, neutral, and unknown place to exist and exhibit their daily occupational engagement in terms of performance areas and context.

Occupational therapy as a profession has been on the fore-front of many situations in this era of the $21^{\text {st }}$ century. This is in line with the advancement of knowledge about our occupational role and contextual practice. The concept of occupational therapy focuses on the management of a displaced person can be traced to broadening the scope of occupational therapy enlightenment as an emergent area of practice [12]. In 2010, a collaborative effort of engagement between physiotherapy and occupational therapy illustrated the key role of occupational therapist involvement in early planning for disaster and implementa- 
tion of disaster relief services.

Intervention and management enhanced on displaced people of post-earthquake in Haiti focus on:

- Direct patient care.

- Adaptive equipment Provision.

- Allocation.

- Education and training.

- Community out reach.

- Logistic or administrative duties [13].

Further-more, in a study conducted by [14] on individualization of disaster planning for students with impaired vision. Attention to details in an emergency evacuation procedure, disaster planning, and emergency preparedness are some of their study focus point that needs to be well-thought at the school level ahead of future or uneventful disaster situation.

This will enhance the knowledge of the students and guide their actions through the basic steps of disaster measures in any uneventful situation where emergency help might not be ascertained.

A critical review of Africa measure to disaster management as postulated by [15] expatiated on the need for:

1) Strong political governance (Imply a skilled administration in all levels of government structures) [16].

2) Internalization of responsibilities (Government should offer strong intervention depending on the scale of the disaster).

3) Specialized capabilities (Disaster risk reduction should become a ministerial function rather than simply a minor function).

4) Problem mitigation (Government must reinforce adequate policies and effective disaster preventive precaution which will enhance further growth and development of the affected areas).

Occupational therapists practitioners through novel knowledge should be able to break through the heart of government at the basic level of the health care system to in co-operate the skill and concept explained above [17]. This can be achieved by a collaborative effort with the primary health care service through efficient training, work shop, symposium, conferences and community orientation practice (community built practice) at different levels of health care services (organizational, community, and population level) [18]. Following a displacement, the occupational therapist can advocate for resettlement of displaced people and provide efficient rehabilitation service to the needful. Once the primary goal of the primary health care service is well established, ideal and implementation can focus on secondary and tertiary institution enlightenment about the inclusion of occupational therapy practitioners as part of disaster team through governmental activities and participation. The ultimate role of occupational therapy at this level is to foster active participation in functional tasks and engagement in productive occupation, play, leisure, and enhance the performance component of displaced people. Furthermore, occupational therapy "Ha- 
bilitation" frame of reference can be in-cooperated as a foundation for disaster management practice with more emphases on:

1) Preparedness.

- Primary health care service.

- Secondary health care service.

- Tertiary health care service.

2) Evacuation procedure.

3) Disaster and confounding factors.

4) Government and Non-governmental organization in-cooperation pre and post disaster events [19].

Displacement in response to disaster events has been one of the essential processes of avoiding various damage to health and life serving measures imbibed by most of the affected individuals. During displacement, people abandoned their usual activities and focus more on resettlement of any kind with-out considering the after math effect of their means of survival. Displacement as illustrated by [20] is the forceful movement of people from their main locality, environment, and occupational activities. A displaced person experiences social changes caused by previously established factors.

\subsection{Displacement of People Can Result from Either}

1) Population displacement.

Population displacement is defined as the mass migration of the people away from their natural habitat due to disaster influence and or problems confronting their hesitance.

- Direct (Displacement of people from their locations).

- Indirect (Lead to loss of livelihood) people are forced to leave the home region to which they are attached.

2) Internally displaced persons (IDPs).

- These are persons or groups of persons who have been forced to flee, or leave their homes, places of habitual residence. People who are forced to flee their homes, often for the very same reasons as a refugee but who remain within their own country and do not cross an international border [21].

\section{Management}

As the disasters are in enormous raise, it is mandatory that the health care professionals are adequately trained to prepare and handle emergency care in the need of time as suggested by World Health Organisation (WHO). Lack of preparedness results in gaps in disaster management. As noted in Oman, vaccum in disaster management was observed during Cyclone Gonu. As prior guidelines were not informed, health personnel were left in a state of confusion and disorganised work [22]. In addition, inadequate training still exists in health care in Oman [23].

To fill the gaps in disaster management, disaster preparedness needs to be in- 
cluded in the curriculum of undergraduate education for occupational therapy and other health professionals so that the graduates are well aware of what measures to be put into action for the effective management of disasters. Further-more disaster management education enhances safety and security of health care workers and thus encourages the willingness of participation by the students during disasters [24]. As a first step, the teaching faculty should be trained through partnerships with agents involved in training personnel for disaster management and intervention for displaced people [25]. Adding to the above, across the countries primary health care system exists in different forms. Through the primary health care system, the local resources could be enhanced including occupational therapy service to act immediately after the disaster has stuck the region by advocating for temporary or permanent resettlements of the affected populations [26]. Hence the disaster preparedness plays a crucial role in disaster management which needs to be addressed.

In lieu with this, people affected by either natural or industrial disasters can be populated or internally displaced away from their grounded environment. These ultimately deprive, disorganize, and psychologically impact negatively on the entire affected people. Occupational therapists in a bid to work and manage a displaced person due to the disaster of any nature should focus on People Environment Occupation Model (PEO) [27]. The People Environment Occupation Model views the person as a dynamic and changing being with skills and abilities to meet roles over time. It is a client-centered approach with an equal emphasis placed on the environment and the occupation when designing the intervention.

The environment includes the physical, social, cultural and institutional factors that influence occupational performance. The occupations perspectives includes self-care, productivity, leisure pursuit, ADL, IADL, rest and sleep, education, play, work, and social participation (OTPF- $3^{\text {rd }}$ ed) [28]. The PEO as illustrated earlier can be a defined source of strength for the occupational therapist working with displaced people due to disasters of various natures because it addresses the individual perspectives within a given environment and functional engagement (occupation). The therapist brings to the context of a displaced person's set of attributes, skills, knowledge, and experience. Roles differ and vary in degree of importance depending on the environment and developmental stage of the person. The focus of analysis is on the behaviour of the person, such as:

- Motivation: interests, cultural relevance of activity.

- Consider situations/conditions that precipitate emotional responses: failure, stress, distraction.

- Degree of autonomy.

Furthermore, all the environmental categories are equally important to consider according to the model. The environment where a displaced person fined them self should be considered from the unique perspective of the person, household, neighborhood, and/or community. Demands and cues about expected and appropriate behaviour are received from the environment conti- 
nuously. The model identifies the areas of occupation as self-care, productivity, and leisure. Occupations are engaged in to satisfy an intrinsic need for selfmaintenance, expression, life satisfaction, and also carried out within multiple contexts in fulfillment of developmentally appropriate roles.

The model is a framework that guides the clinical reasoning of the therapist in analysis and understanding of the interdependent interaction of a displaced person with his/her environment and therefore can form a foundation for application in practice. Although, the model does not prescribe a set of assessments or provide intervention guidelines, therefore allows the use of other occupational therapy assessment tools and interventions based on practice demands.

When analysing occupations of the displaced person due to disaster, the focus should be on characteristics of tasks (occupation), degree of structure, duration of the activity, the complexity of tasks, and characteristics of task demands of the person or population involved [29]. PEO as relevant to disaster and displaced people can be better established with further analysis through Ecology of Human Performance (EHP) [30].

1) The EHP stresses on person, the task (activity demands), and the context. The occupational performance is intertwined with, and the product of, the interaction of these variables. As related to PEO and displaced individuals EHP analyses the person and their present environment within the limit of person performance post disaster nature (emphasis on the residual performance pattern and capacity of the affected person). Since the PEO does not focus the occupational performance of a displaced person, the EHP addresses the features and context of displacement which would enable occupational therapists to plan and execute appropriate intervention measures. Intervention is a collaborative process between the person, the family, and the occupational therapist and the main goal is to facilitate occupational performance with in the patient's new or residual environment.

There are five therapeutic intervention strategies presented by the framework. These are, establish/restore, adapt, alter, prevent, and create.

a) Establish/Restore - this occurs at the level of the person, where skills and abilities are the focus of intervention. The aim is to restore function by improving abilities and skills. This remediation process takes place within a context.

b) Alter-intervention focuses on selecting a context that would enable performance with the person's current skills and abilities. This entails finding a suitable context rather than changing the present context to meet abilities.

c) Adapt - the context manipulated and structured to support performance. Task demands can also be adapted to enable performance.

d) Prevent - the occurrence or evolution of maladaptive performance is prevented. Prevention is the main focus of intervention. This could be done by addressing features of the person, task and context that could leads to the occurrence or evolution of maladaptive performance.

e) Create-circumstances that promote more adaptable or complex perfor- 
mance within the context are created. This intervention strategy is orientated towards the overall promotion of functional performance without the assumption that disabilities could occur or interfere with performance [31].

2) The PEO is a transactional model with five essential concepts:

- Person.

- Environment.

- Occupation.

- Occupational Performance.

- Person-Environment-Occupational fit.

Furthermore, there are seven assumptions to practice in line with PEO and application to displaced person due to disaster. Viz-a-viz:

- The person is dynamic and always developing and interacting with the environment.

- The environment changes and so does individual behavior does.

- The environment can have enabling or constraining effects on occupational performance.

- The environment is often easier to change than the person.

- Occupations are complex.

- The relationship between the PEO is transactional.

- Occupational performance changes over the life span. As relevant to disaster and displaced person.

- The psychological influence of displacement can lead to behavioral problems and social prejudice.

- Displaced persons are highly prone to environmental constraining in physical, architectural, social, cultural, and institutional effects.

- Social withdrawal, lack of participation, and social isolation are a few of the changes that occur to displaced people due to environmental challenges.

- The occupational performance of an individual can be drastically affected due to the negative effect of the disaster focusing on life achievement, occupation, resources, health, and wellness. For instance, (Figure 2).

Person

- Unique being with a variety of roles.

- Believe in the worth of persons regardless of disability, age, developmental difficulty, or social condition.

- Approach the person from a holistic point of views (meaningless to attend to parts of a person in isolation from other people and the environment).

- Person is viewed holistically-mind, body, and spirit.

- The "Person" can refer to an individual, group, organization, or community Performance components of person as related to displacement.

- Motor.

- Process.

- Cognitive/Perceptual.

- Communication/Interaction. 
- Sensory and sensory motor processes [32].

3) The PEO Model frame work application to disaster management and displacement of peoples. It focuses on Figure 3.

4) Assessment of Occupational Performance Goal. This is illustrated in Figure 4.

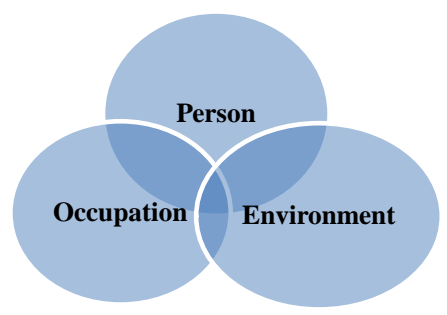

Figure 2. People environment occupation sketch.

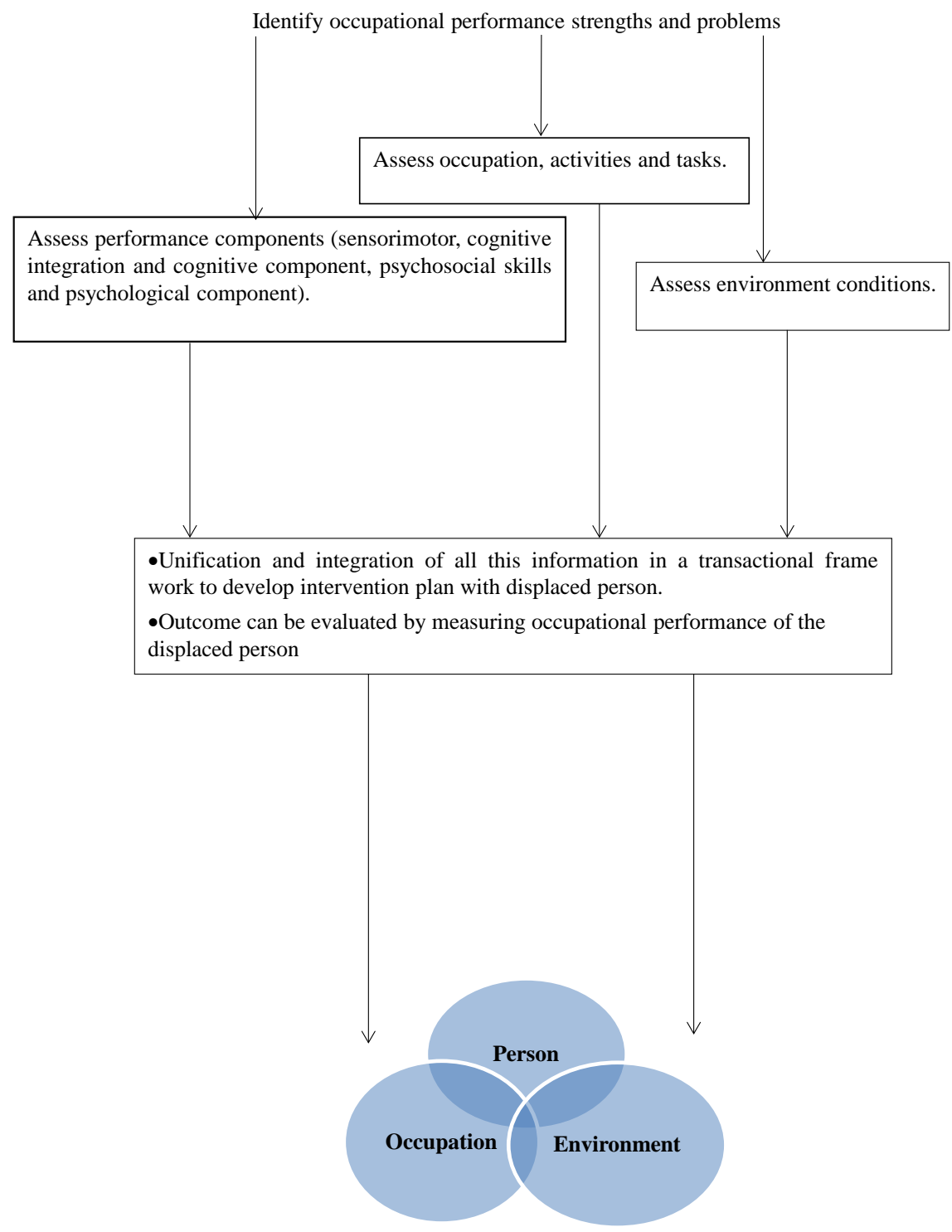

Figure 3. The PEO Model's application frame work to disaster management and displacement of peoples. 


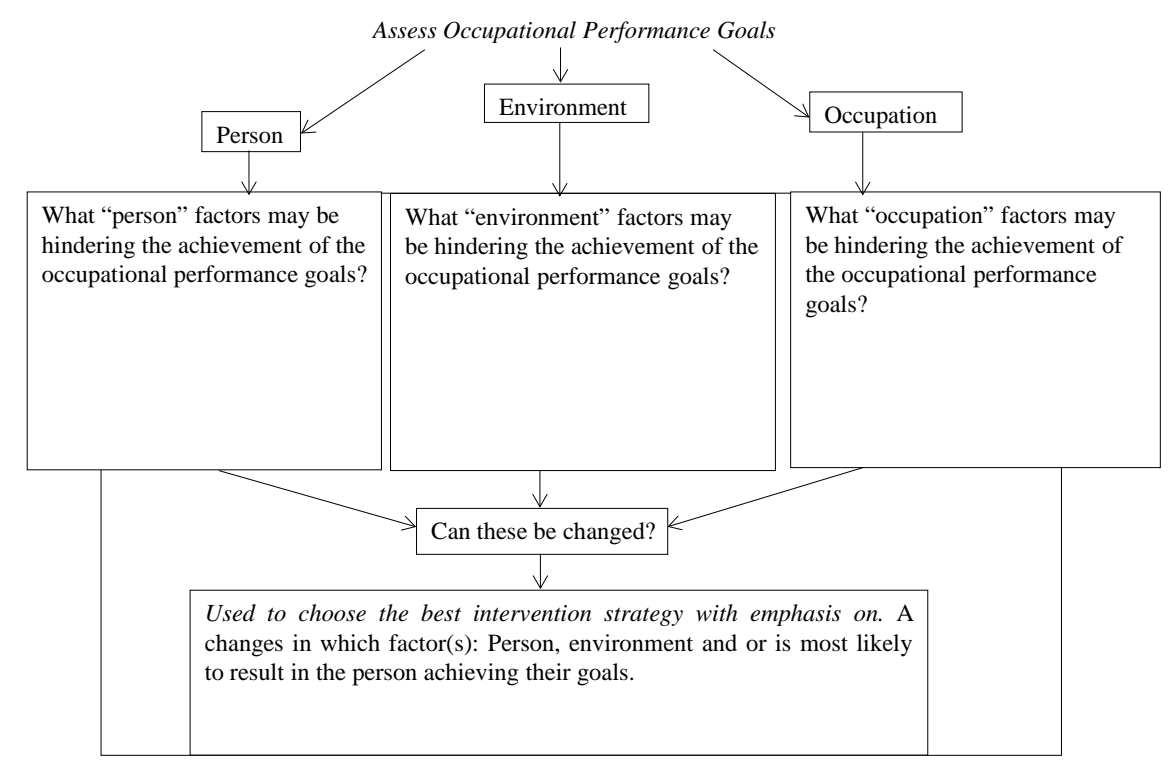

Figure 4. Assessment of occupational performance goal.

According to [33] on application of PEO as complex dynamic relationships between people, occupations, and environment, the therapists must communicate their practices and how their practices influences outcome. This study talks about how a particular model helps therapist to conceptualize, plan, communicate and evaluate occupational performance interventions and to serve as a tool for therapist to use in client(s) - therapists alliances to enable persons to successfully engage in meaningful occupations in chosen environment.

This concept can be applied to a displaced person, in that, the ability of the therapist to integrate and facilitate progress in terms of PEO in a displaced person and re-establish their productivity, life role, social participation, occupational engagement through various strategies relevant to occupational therapy practice [34].

The therapist must be aware of both the limitations of the person and task demands so that the person can organize their environment in compliance with task. The occupational therapy process is the client-cantered delivery of OT services. This is in line with the PEO focusing on displacement of person due to disaster nature [35].

\section{Conclusion}

In conclusion, this methodological paper presents the role of occupational therapist practice guideline for displaced people due to disaster of any nature. The paper focuses on application of People Environment and Occupation as intervention method through client centre practice with key emphases on person (individual, community or population) environment and occupation. Furthermore, the study illustrates integration of Ecology of Human Occupation in to the practice guideline for displaced person because POE focuses more on the occupation and person which enable the use of multiple standardize contextual assessment 
format and intervention protocol. The introduction of Ecology of Human Occupation serves as a frame work to analysis the performance levels of displaced people within their context of hesitance. Both occupation based approach needs to be integrated together as a single concept to aid optimum performance of a displaced person because occupational therapy practice focuses on the use of occupations to promote health, wellbeing and participation in life [36].

\section{Acknowledgements}

To the Glory of Almighty God, for he has never failed me. I would like to express my deepest gratitude to the co-authors, contributors, adviser, and guidance of this write-up. A special thanks to Mrs Silpa Immanuel Voola for her immeasurable effort, Dr. U.Ganapathy Sankar and Pastor Adedoye of The Redeemed Christian Church of God, Chennai for their assistance in making this paper a success.

\section{Conflicts of Interest}

The authors declare no conflicts of interest regarding the publication of this paper.

\section{References}

[1] United Nations Office for Disaster Risk Reduction (2009) United Nations General Assembly. United Nations, Geneva.

[2] Herlander, M.L., Andreilcy, A.B., Adilson, P., Abel, M.L. and José, A.A. (2013) Impacts of Natural Disasters on Environmental and Socio-Economic Systems: What Makes the Difference? Ambiente \& Sociedade, 16, 45-64. http://dx.doi.org/10.1590/S1414-753X2013000300004

[3] Diarmid, L. and Carlos, C. (2007) Climate Change and Developing-Country Cities: Implications for Environmental Health and Equity. Journal of Urban Health, 84, 109-117. https://doi.org/10.1007/s11524-007-9170-x

[4] EUR-Lex (2013) Communication from the Commission to the European Parliament, the Council, the European Economic and Social Committee and the Committee of the Regions: An EU Strategy on Adaptation to Climate Change. COM/2013/0216 Final, 52013DC0216, EUR-Lex, Brussels.

[5] Jonathan, W. and Mohammed, M. (2016) International Federation of Red Cross and Red Crescent Societies: World Disaster Report 2006. Satigny/Vernier, Geneva.

[6] Debarati, G.S., Philippe, H., Pasacline, W. and Regina, B. (2016) Annual Disaster Statistical Review 2016: The Numbers and Trends. Centre for Research on the Epidemiology of Disasters: Institute of Health and Society, Brussels.

[7] Lukamba, M.T. (2010) Natural Disasters in African Countries: What Can We Learn about Them? The Journal for Transdisciplinary Research in Southern Africa, 6, 478-495. https://doi.org/10.4102/td.v6i2.266

[8] Rajiv, D.K., Panda, P.C. and Medhabati, K. (2010) Disaster Preparedness among the Resident Community: A Case Study of Rajiv Gandhi University, Itanagar, India. International Journal of Environmental Sciences, 2, 1632-1642.

[9] Valerie, A. (2011) Displacement Due to Natural Hazard-Induced Disasters: Global Estimates for 2009 and 2010. Norwegian Refugee Council, Oslo, Châtelaine (Gene- 
va).

[10] Regina, B., CRED A., Munich, R., Debarati, G. and CRED. (2009) Disaster Category Classification and peril Terminology for Operational Purposes: Common accord Centre for Research on the Epidemiology of Disasters (CRED) and Munich Reinsurance Company (Munich RE). WHO Collaborating Center for Research on the Epidemiology of Disaster.

[11] Odeyoyin, Y.A., Adekanmbi, O.C. and Sana, A. (2018) Disaster Has Been Happening Logically Due to: Government/Political Influence Affecting the Economic and Security of the Involved Nation. Unpublished Manuscript, SRM College of Occupational Therapy, Kattankulathur.

[12] Odeyoyin, Y.A., Adekanmbi, O.C. and Sana, A. (2018) Advancement in Knowledge about Occupational Role and Contextual Practice. Unpublished Manuscript, SRM College of Occupational Therapy, Kattankulathur.

[13] Susan, K. and Jennifer, A. (2013) The Roles, Barriers, and Experiences of Physical and Occupational Therapists in Disaster Relief: Post-Earthquake Haiti 2010. Physical Therapy Faculty Publications, 1-9.

[14] Good, G.A. (2015) Emergency Plans in Schools: Individualised Disaster Planning for Students with Impaired Vision. Journal of the South Pacific Educators in Vision Impairment, 8, 17-28.

[15] The World Bank, Global Facility for Disaster Reduction and Recovery (2010) Report on the Status of Disaster Risk Reduction in Sub-Saharan Africa.

[16] United Nations (2011) Executive Board of the United Nations Development Programme and of the United Nations Population Fund: UNDP Strategic Plan, 2008-2011 Accelerating Global Progress on Human Development. DP/2007/43/Rev.1, United Nations, Geneva.

[17] Odeyoyin, Y.A., Adekanmbi, O.C. and Sana, A. (2018) The Occupational Therapists practitioners: Through Novel Knowledge Should Be Able to Break through the Heart of Government at the Basic Level of Health Caresystem to in Cooperate the Skill and Concepts of Disaster Preparedness. Unpublished Manuscript, SRM College of Occupational Therapy, Kattankulathur.

[18] American Occupational Therapy Association (2014) The Occupational Therapy Practice Framework: Domain and Process. 3rd Edition, American Occupational Therapy Association, Bethesda.

[19] Odeyoyin, Y.A., Adekanmbi, O.C. and Sana, A. (2018) Occupational Therapy 'Habilitation' Frame of Reference: Can Be In-Cooperated as a Foundation for Disaster Management Practice. Unpublished Manuscript, SRM College of Occupational Therapy, Kattankulathur.

[20] United Nations Educational, Scientific and Cultural Organization (2017) Migration and Inclusive Societies.

[21] United Nations Office for Disaster Risk Reduction (2017) United Nations General Assembly. United Nations, Geneva.

[22] Al-Shaqsi, S. (2010) Care or Cry: Three Years from Cyclone Gonu. What Have We Learnt? Oman Medical Journal, 25, 162-167. https://doi.org/10.5001/omj.2010.50

[23] Al-Shaqsi, S., Gauld, R., McBride, D., Al-Kashmiri, A. and Al-Harthy, A. (2014) The state of Healthcare Disaster Plans in New Zealand and the Sultanate of Oman: An International Comparative Analysis. Advanced Emergency Medicine, 2014, Article ID: 758728. https://doi.org/10.1155/2014/758728

[24] Chapman, K. and Paul, A. (2008) Disaster Preparedness in the Acute Setting: Are 
Nurses Ready? Australasian Emergency Care, 11, 135-144. https://doi.org/10.1016/j.aenj.2008.04.002

[25] Halstead, J.A. (2013) When Disaster Strikes: Are You and Your Nursing Students Prepared? Nursing Education Perspectives, 34, 213. https://doi.org/10.1097/00024776-201307000-00001

[26] Jveria, S.M., Pedro, A.G. and Rafael, C.D. (2017) Disaster Management and Primary Health Care: Implications for Medical Education. International Journal of Medical Education, 8, 414-415. https://dx.doi.org/10.5116/ijme.5a07.1e1b

[27] Odeyoyin, Y.A., Adekanmbi, O.C. and Sana, A. (2018) Occupational Therapists in a Bid to Work and Manage a Displaced Person Due to Disaster of Any Nature Should Focus on: People Environment Occupation Model (PEO). Unpublished Manuscript, SRM College of Occupational Therapy, Kattankulathur.

[28] Winifred, S.K. and Heidi, M.P. (2013) Pedretti's Occupational Therapy for Physical Dysfunction: The Occupational Therapy Process. 7th Edition, Mosby Elsevier Inc., St. Louis.

[29] Mary, L. Susan, S. and Barbara, C. (1996) The Person-Environment-Occupation Model: A Transactive Approach to Occupational Performance. Canadian Journal of Occupational Therapy, 63, 9-23. https://doi.org/10.1177\%2F000841749606300103

[30] Odeyoyin, Y.A., Adekanmbi, O.C. and Sana, A. (2018) PEO as Relevant to Disaster and Displaced People Can Be Better Established with Further Analysis through: Ecology of Human Performance (EHP). Unpublished Manuscript, SRM College of Occupational Therapy, Kattankulathur.

[31] Dunn, W., Brown, C. and McGuigan, A. (1994) The Ecology of Human Performance: A Framework for Considering the Effect of Context. The American Journal of Occupational Therapy, 48, 595-607. https://doi.org/10.5014/ajot.48.7.595

[32] Gayle, I.H., Nancy, K.L. and Margaret, S.C. (2005) Activity Analysis: Application to Occupation. Slack Incorporated, New York.

[33] Susan, S., Patty, R., Debra, S., Mary L., Lori, L. and Barbara, C. (1999) Application of the Person-Environment-Occupation Model: A practical Tool. Canadian Journal of Occupational Therapy, 66, 122-133. https://doi.org/10.1177\%2F000841749906600304

[34] Odeyoyin, Y.A., Adekanmbi, O.C. and Sana, A. (2018) This Concept Can Be Applied to a Displaced Person: Re-Establish Their Productivity, Life Role, Social Participation, Occupational Engagement through Various Strategies Relevant to Occupational Therapy Practice. Unpublished Manuscript, SRM College of Occupational Therapy, Kattankulathur.

[35] Odeyoyin, Y.A., Adekanmbi, O.C. and Sana, A. (2018) The Occupational Therapy Process: In Line with the PEO Focusing on Displacement of Person Due to Disaster Nature. Unpublished Manuscript, SRM College of Occupational Therapy, Kattankulathur.

[36] Odeyoyin, Y.A., Adekanmbi, O.C. and Sana, A. (2018) Occupational Therapy Occupation Based Approach: Can Be Integrated as a Single Concept to Aid Optimum Performance of Displaced Person to Promote Health, Wellbeing and Participation in life. Unpublished Manuscript, SRM College of Occupational Therapy, Kattankulathur. 